\title{
EDITORIAL
}

\section{REDES SOCIALES EN PERSPECTIVA HISTÓRICA: CASOS DE ESTUDIO EN SURAMÉRICA, SIGLOS XVII-XX}

\author{
SOCIAL NETWORKS IN A HISTORICAL PERSPECTIVE: \\ CASE STUDIES IN SOUTH AMERICA, XVII-XX CENTURIES
}

\author{
Víctor Brangier
}

La noción de red, como lente específico para el escrutinio de las fisonomías que adquieren las relaciones sociales, confunde sus orígenes con las raíces de las ciencias sociales. En efecto, el Análisis de Redes Sociales (ARS) proviene de la sociología y de la antropología y circunscribe como área de estudio las relaciones entre individuos, grupos de individuos o instituciones que se analizan como nodos insertos en una estructura mayor denominada red. El examen parte desde el flujo de una "sustancia relacional" concreta, como información, influencias, bienes materiales $\mathrm{u}$ otros recursos que implican capital para los actores insertos en la red y que lo intercambian en su interior. El enfoque postula que las motivaciones y conductas de los sujetos interactuantes se motivan por la posición que ocupan dentro de la estructura, más que por iniciativa individual o por identidades preexistentes. La teoría de redes tuvo su origen en el contexto del estructuralismo sociológico de la década de 1950, aunque alcanzó un cenit en la década de 1970 con la incorporación de métodos matemáticos en la medición de las redes y con el pronóstico estadístico del comportamiento de sus variables (Lozares 1996). El post-estructuralismo presentó un desafío al modelo e impulsó considerar variables más subjetivistas como el interés de los individuos-nodos por acceder a mayores cuotas de recursos dentro de la red (Putnam 2002). Si bien, la posición desigual de los individuos-nodos en la red permitía explicar su conducta oscilante entre la colaboración y la competencia (Uribe 2014), lo cierto es que en los últimos años ha sido necesario enriquecer la explicación con la incorporación de otros niveles de indagación como el cambio de la red en el tiempo, la construcción intersubjetiva del interés y las motivaciones cooperativas más que utilitarias-individualistas (Martins 2009).

En historiografía, la noción de red como herramienta teórico-metodológica enfrenta algunas singularidades. A la fragmentariedad intrínseca de las fuentes de archivo, debe sumarse la porosidad constitutiva del nuevo punto de llegada: la red. Doble fisura del trabajo que eleva la conjetura del observador a un nivel protagónico, pues debe decir algo de los actores, de sus vínculos y de los espacios vacíos - mayoritarios- que considera cada red de relaciones (Hering 2018). Este tipo de abordajes tomó un impulso en América Latina desde la década de $1970^{1}$. Desde entonces en la región, las investigaciones han hecho uso del enfoque para escudriñar las tácticas relacionales presentes en las sociedades "tradicionales". Los estudios se han centrado en las redes de vinculación que envolvía dos unidades históricas de análisis: las familias de elites locales y los comerciantes y productores asociados directa o indirectamente con esas familias ${ }^{2}$. El sesgo parece reflejar la inclinación que asumieron desde un principio tradiciones historiográficas de otras latitudes ${ }^{3}$. Sin embargo, el estudio histórico de las redes sociales pareciera cargar varias deudas y desafíos por afrontar. No solo considerando el ritmo acelerado de discusión que hoy predomina en las Ciencias Sociales (y en el ARS interdisciplinario que han construido desde el diálogo con las ciencias de la información y el data mining que estas proveen ${ }^{4}$ ), sino además asumiendo que la utilización del concepto de red en los estudios históricos se registran en América Latina hace más de medio siglo, como se señaló.

Tal vez uno de los retos más evidentes sigue siendo el abordaje sistemático de aquellos sectores

\footnotetext{
* Universidad Bernardo O’Higgins (Centro de Estudios Históricos), Chile. Coordinador Proyecto HISONET (History \& Social Network).
} 
que no pertenecían directamente a las elites ${ }^{5}$. Pero no es el único. En este sentido, este dossier aspira contribuir un grado, compartiendo problemas, preguntas y evidencias de archivo respecto a la acción y presencia de actores insertos en estructuras relacionales y provenientes de los más diversos estratos y sectores sociales. Claro está, no con el objeto de proponer una mirada dicotómica "redes por arriba" v/s "redes por abajo". En cambio, como lo demuestran las contribuciones aquí reunidas, para arrojar luces sobre los encuentros, los circuitos y nexos entre actores, agentes e incluso, entre redes formales e informales de la más diversa proveniencia. Desde esta óptica, es posible adelantar que los autores partícipes en esta compilación han levantado un esfuerzo significativo por maximizar el enfoque relacional en sus propios nichos de estudio.

Los siete artículos que integran este número examinan experiencias relacionales que atravesaron distintas latitudes de Suramérica, en coyunturas que abarcaron entre fines del siglo XVII y principios del siglo XX. No obstante la heterogénea gama de tiempos, espacios, sujetos y objetos de estudio, en el dossier asoman tres ejes que apuntan a dilucidar cuestiones de difícil visualización sin el enfoque relacional y sin la utilización de la noción de red.

Un primer lenguaje común de los artículos es la observación del norte de la vinculación. En este sentido, las propuestas no pierden de vista la conciencia de actores que, ya sea por estrategia, por política, por sobrevivencia o por el despliegue consistente de un saber práctico, se vinculaban unos con otros con tal de conquistar ciertos propósitos o cumplir con determinadas expectativas. Así lo evidencia la contribución de Luz Huertas, al rastrear las alianzas informales emprendidas por el mundo popular, en Lima de fines del siglo XIX, con tal de desplegar instancias de vigilancia y contención social. Del mismo modo lo grafica Darío Barriera, examinando los intentos de coordinación comunicativa entre el Virrey del Perú, la gobernación del Río de la Plata y ministros de la corte peninsular a fines del siglo XVIII, para avanzar en la comprensión y defensa de las islas Malvinas. En esta senda se inscribe el trabajo de Natalia Urra, enfocado en las cadenas de sociabilidad de actores marginados en Lima virreinal, en el tránsito del siglo XVII al XVIII. Sujetos anudados unos con otros en torno a prácticas de hechicería, a fin de satisfacer necesidades impuestas por su propia condición de subalternidad.
Las distintas piezas del dossier sitúan en un primer lugar el plano consciente y la agencia de los actores que diseñan objetivos para actuar en red. Es la propuesta que atraviesa el abordaje de Aude Argouse, quien también perfila un objetivo de territorialización del dominio, presente en la cadena de distribución del papel sellado en el reino de Chile en el siglo XVIII. El estudio de Diego Galeano tampoco es ajeno al propósito definido que tenía la coordinación entre detectives y policías de diferentes ciudades de Suramérica a principios del siglo XX: superar los propósitos de esas otras redes y circuitos compuestos por falsificadores de billetes y sus cómplices. La monografía de Francisco Betancourt, por su parte, no soslaya el cálculo estratégico de comerciantes y actores del gobierno post independentista de Bernardo O'Higgins, en Chile, por enlazarse mutuamente para conquistar nichos de mercados y negocios, los unos, y para cubrir los vacíos de erario público, los otros, en una coyuntura crítica de rearticulación comercial y de reconstrucción gubernamental. Finalmente, la red de venta de tierras que visualiza Víctor Brangier, en un espacio rural de la zona central de Chile en la primera mitad del siglo XIX, enfatiza la estratagema de actores clave (brokers medianos propietarios) por conquistar capital social, privilegiando lazos con actores mal vinculados y de baja renta.

Un segundo momento transversal en el dossier es la diversidad en la procedencia de los sujetos que conforman las redes. Sin duda en este nivel las contribuciones enfrentan de manera más directa el desafío que asume la historiografía regional que se apoya en el enfoque red, según se puntualizó más arriba. En este sentido, los estudios cuestionan la tendencia a la homofilia (la asociatividad entre similares: igual clase, género, condición física, ideología, etnia, etc.), uno de los credos más longevos del ARS (Kadushin 2012: 18-20). La naturaleza desemejante de las redes queda al descubierto en la propuesta de Diego Galeano, quien indaga en la heterogeneidad de actores (y por tanto de expectativas e intereses) que quedaban envueltos en la pesquisa y captura de falsificadores de billetes. Allí convergían agentes encubiertos y policías de ciudades como Rio de Janeiro, Buenos Aires, Montevideo o Santiago, pero también reporteros de la prensa gráfica. Del mismo modo, la propuesta de Víctor Brangier insiste en señalar que la red de venta de tierras en el valle de Pichidegua en Chile, articuló transacciones entre propietarios de un muy amplio 
rango de rentabilidad. Y Natalia Urra da inicio a su propuesta subrayando el crisol étnico y cultural que constituye el hábitat de sus ocho personajes que protagonizaron las redes de hechicería y sortilegio en la ciudad sede del virreinato peruano.

Redes diversas, en las que parecía importar más las funciones y jerarquías que se fueron tejiendo desde los circuitos y relaciones más que la estratificación existente antes de la acción en red. Una heterofilia relacional que queda al descubierto además en el artículo de Francisco Betancourt, donde sale a la superficie que los comerciantes, con tal de volverse financistas del novel estado republicano, debieron tejer pactos con una variopinta gama de agentes comerciales, de gobierno, de aduanas, de las milicias, etc. O también en la contribución de Darío Barriera, al identificar que los actores aglutinados en torno al rumor y noticias de la ocupación británica de las islas Malvinas (y, por tanto, respecto a las líneas de acción a seguir) eran agentes de los distintos escalafones de la monarquía hispana y sus posesiones en Suramérica. Incluso más, la cuestión del archipiélago, como indica Barriera, "comienza a ser un tema permanente de conversación entre miembros de la corte, el Rey, alguno de sus virreyes, gobernadores, jefes de sus fuerzas militares, grandes comerciantes, viajeros, eruditos". De modo similar, Aude Argouse puntualiza la diversidad de agentes y autoridades locales con quienes se debió comunicar Ignacio de los Olivos (Tesorero del papel sellado en Chile entre 1739 y 1770) para propiciar la distribución de este objeto que se habría constituido en el "principal soporte material de la cultura jurídica". Coordinación y lazos entre desiguales, como lo corrobora Luz Huertas en su caso de estudio, donde la coordinación social establecida en los barrios, incluían aún vínculos con agentes de la policía, yuxtaponiendo circuitos informales con aquellos más formales (o con aspiraciones a serlo, dadas las precariedades operacionales de la policía limeña finisecular) en el control de los ilícitos.

Una tercera propuesta vertebral de las contribuciones es la fragilidad de las redes, abiertas al cambio tras la consideración de sus conflictos, negociaciones y desgarros intestinos o repentinos. Tal vez en este sentido, estas monografías explotan uno de los tributos específicos que nuestra disciplina le brinda a la noción de red (pues ya se ha reflexionado con insistencia del aporte inverso): su mutabilidad y finitud. Pues querámoslo o no, debido a que la materia prima de las redes en la historia fueron personas, se trató de redes signadas desde un principio con el presagio de su propia muerte. Desde esta perspectiva, los estudios históricos que avanzan en la mirada relacional, no pierden de vista la durabilidad de los nexos. Este se torna uno de los desafíos más complejos para las Ciencias Sociales y para el ARS, que se esfuerzan en la rigurosidad de estudios longitudinales, para detectar los cambios en y de las redes. Pero para el quehacer historiográfico, la cuestión del cambio le resulta más próximo y quizás, hasta consustancial.

La vulnerabilidad intrínseca de las relaciones y el conflicto crónico del que están henchidas, se descubre en la presentación de Francisco Betancourt. En la convergencia entre redes informales de comerciantes y un gobierno con pretensiones de formalidad, se abría una fisura: las acusaciones por corrupción, sobre todo contra la "figura clave para la conformación de la red", el ministro de hacienda de Bernardo O'Higgins, Antonio Rodríguez Aldea, quien servía de bisagra para articular los contactos. Pistas similares figuran en el estudio de Diego Galeano, quien da cuenta de que las redes de falsificadores de billetes estaban atravesadas por delatores dispuestos a colaborar con los detectives. Pero además, en la otra vereda, los detectives y policías debían lidiar con la demanda de noticias de los reporteros con quienes debían vincularse a través de noticias ambiguas o derechamente falsas, con tal de garantizar el secreto de las investigaciones. El examen de Darío Barriera, sobre la preocupación y revalorización geopolítica de las islas Malvinas en la medianía del siglo XVIII, también manifiesta las debilidades de aquel circuito de agentes de la monarquía hispana que vehiculizaba saberes, noticias y propuestas sobre el archipiélago. El autor, por ejemplo, culmina anunciando una posibilidad: el Virrey del Perú, Manuel Amat y Junyent podría haber estado interesado en desvincularse de estos nexos, proponiéndole al rey la división del virreinato para quedar al margen de la jurisdicción de aquel problemático territorio marítimo.

El hecho de redes vulnerables se encuentra, por cierto, en el texto de Natalia Urra. Las historias de vida que persigue la autora, alcanza a sujetos trashumantes, que se desplazaron desde ciudades y latitudes lejanas hasta la Lima virreinal, portando conocimientos sobre la hechicería y el sortilegio y, allí, en la ciudad, articularon su red de relaciones. Sujetos que transitaban, parecían constituir, a la 
larga, escenarios relacionales también transitorios. El aporte de Luz Huerta, a su vez, evidencia la simbiosis posible entre redes sociales de carácter popular, también en Lima, pero esta vez a fines del siglo XIX, y la institucionalidad policial en construcción. Sin embargo, como enfatiza, ambos circuitos, si bien lograban instancias de colaboración (como el arresto social del criminal y la derivación policial hacia el juzgado), también entraban en conflicto y negociaban los términos de aquella colaboración. Paralelamente, el artículo de Aude Argouse no soslaya las dificultades operacionales de la circulación del papel sellado en el reino de Chile. En efecto, como precisa la autora, el mismo Tesorero del papel sellado, Ignacio de los Olivos, se quejaba de la siempre dificultosa articulación entre autoridades locales, carentes de preparación, para permitir la circulación del papel oficial. Por ello es que, desde este estudio de caso en particular, Argouse refiere que la red que tejió De los Olivos para la movilización del papel sellado en el reino de Chile estaba "bajo la amenaza permanente de la quiebra individual de sus integrantes". De un modo análogo, Víctor Brangier asume la transitoriedad de la red de venta de tierra, surgida en un periodo breve de reconfiguración en las prácticas de acceso a la tierra. Una estructura relacional que se desplegó tras los convulsos años de la independencia de Chile, que tuvieron a la zona central como escenario de batallas; pero que necesariamente debió reformularse con el alza en el valor de la tierra, que despuntó desde 1850 en adelante tras el incremento en la demanda internacional del trigo.

El dossier vehicula entonces siete miradas sobre formas y posibilidades de redes y circuitos relacionales en contextos diversos en Suramérica. Con paradas puntuales en siete coyunturas específicas, entre fines del siglo XVII y principios del siglo XX, los autores abordan viejos temas (geopolítica y gobierno imperial, vigilancia urbana, control social, persecución de ilícitos, mercados de tierra y construcción de las nuevas repúblicas). Sin embargo se trata de tópicos puestos al trasluz desde el enfoque relacional. Redes y circuitos preñados del propósito de sus agentes por vincularse unos con otros, pero también constituidos desde la diversidad y la fragilidad propia de su inscripción en el tiempo.

\section{Referencias Citadas}

Balmori, D. et al.

1990 Las Alianzas de familias y la formación del país en América Latina. FCE, México.

Bertrand M.

1999 "De la familia a la red de sociabilidad". Revista Mexicana de Sociología 61, 2: 107-135.

Bertrand, $\mathrm{M}$.

2011 "Introducción: ¿en qué punto se encuentra el análisis de redes en Historia?". Redes 21, 1: 1-12.

Brading, D.

1975 Mineros y comerciantes en el México borbónico (17631810). FCE, México.

Brangier, V.

En prensa. Intermediación y Grado en una red de venta de tierras. Valle de Pichidegua, Chile, 1820-1835. Caravelle. Cahiers du monde hispanique et luso-brésilien 111.

Hering, M.

2018 "Microhistoria: vía específica de la historia cultural. Prácticas, redes y conjeturas". En Historia Cultural hoy: 13 entradas desde América Latina, editado por V. Brangier y E. Fernández. Prohistoria, Rosario.

Imízcoz, J.M.

2009 "Las redes sociales de las élites. Conceptos, fuentes y aplicaciones". En Las elites en la época moderna: la monarquía española. Vol 1. Nuevas perspectivas, editado por E. Soria, et al., pp. 7-111. Servicio de Publicaciones, Universidad de Córdoba, Córdoba.
Kadushin, Ch.

2012 Understanding Social Networks. Theories, Concepts and Findings. Oxford University Press, New York.

Langue, F.

1999 Los señores de Zacatecas. Una aristocracia minera del siglo XVIII novohispano. FCE, México.

Lowenthal, $\mathrm{M}$.

1976 "Kinship politics in the Chilean independence movement". The Hispanic American Historical Review, 56, 1: $58-80$.

Lozares, C.

1996 "La teoría de redes sociales". Papers 48: 103-126.

Martins, $\mathrm{P}$.

2009 "Redes sociales: un nuevo paradigma en el horizonte sociológico". Cinta Moebio 35: 88-109.

Putnam, R.

2002 Comunidade e democracia: a experiencia da Itália moderna. Fundação Getúlio Vargas, Rio do Janeiro.

Sanjurjo, I. y López, G.

2015 "Las redes de parentesco y el gobierno de la ciudad (Mendoza, siglo XVIII)". Acerca de Las tres casas reinantes de Cuyo del Prof. Jorge Comadrán Ruiz. Revista de Historia Americana y Argentina 50, 1: 11-28.

Uribe, A.

2014 "La teoría de las redes sociales en los estudios históricos. Aportaciones para el estado de la cuestión". Ideas Presentes. Revista estudiantil de la Universidad Autónoma de Baja California, s/p. 


\section{Notas}

1 Fueron pavimentando el camino, entre varias otros, las propuestas de Francois X. Guerra, respecto a la estructuración de redes sociales de las elites hispanoamericanas tardo-coloniales (Sanjurjo y López 2015: 13). También el estudio de Mary Lowenthal (1976) sobre el predominio de las redes familiares en la Independencia chilena o las contribuciones de Diana Balmori (1990) relativas a las estrategias de redes de familias rurales nobiliarias para conquistar tierras y prestigio; Un examen del campo de discusión particularmente en y sobre Brasil, en (Ferreira de Andrade 2014: 26).

2 En otra oportunidad hemos avanzado un esfuerzo por sintetizar los principales hitos de esta discusión (Brangier en prensa); Para el caso de las redes de elites mineras tardo colonial (Brading 1975; Langue 1999).

3 A una evaluación similar llegó Imízcoz (2009) en el escrutinio de la literatura española sobre historia y redes; Bertrand (2011) diagnosticó para la misma época el uso de la noción de red en la historiografía europea. Indicó que de la mano de la microhistoria italiana y francesa emergió una serie de estudios preocupados por el fenómeno relacional como actor histórico en sí mismo. Aunque siempre desde la perspectiva micro y destacando la agencia individual. Bertrand concluye que esta última orientación implicó una desconexión con el análisis estructural macro que ensayaban por aquel tiempo las Ciencias Sociales mediante el método ARS.

4 Tal vez uno de los mejores ejemplos de este esfuerzo de coordinación en la región, lo ofrece Interdisciplinary Networks Research Center (INTERACT), alojado en la Universidad de los Andes, en Bogotá. Remito al lector a: https://interact.uniandes.edu.co/?page_id $=20$

5 Por supuesto, también deviene palmaria la necesidad de trascender el uso metafórico de la noción de red para saltar al análisis intestino de la estructura. En efecto, salvo sugerentes esfuerzos que se han adentrado en el método ARS en perspectiva histórica, pareciera ser que la disciplina en la región no ha trazado puentes para el diálogo con el campo fecundo del ARS y su institucionalidad anexa. De todos modos, la identificación de esta "deuda" que aquí proponemos no tiene nada de novedosa. Ya la había subrayado hace dos décadas Michel Bertrand (1999: 133). 